\title{
Safety culture: a perpetual challenge or an opportunity for Romanian companies?
}

\author{
Roland Iosif Moraru ${ }^{1 *}$, Gabriel Bujor Băbuţ $^{1}$, Lucian - Ionel Cioca ${ }^{2}$, Mihai Popescu- \\ Stelea ${ }^{1}$, and Victor-Gabriel Vasilescu ${ }^{1}$ \\ ${ }^{1}$ University of Petroşani, Faculty of Mines, Department of Management and Industrial Engineering, \\ University Street, number 20, Petrosani, Romania \\ ${ }^{2}$ "Lucian Blaga" University of Sibiu, Faculty of Engineering, Department of Industrial Engineering \\ and Management
}

\begin{abstract}
The main objective of the paper is to analyze the safety culture in order to understand how theory and practice can be integrated to improve safety performance and related economic outcomes. The research includes the synthesis of systematic studies on safety culture and the factors that influence the relationship between organizational culture and safety behavior. In a global manner, the results obtained generate relevant insights into how safety culture can be theoretically systematized and provide a series of recommendations that can guide the development of future safety culture interventions. Finally, a framework is proposed for an in-depth understanding of all the implications of safety culture in the practice of Romanian companies.
\end{abstract}

\section{Introduction}

European companies of all types achieved significant improvements in terms of safety and health $(\mathrm{OSH})$ in recent decades. These improvements are due in part to the recognition by employers that taking an active leading role in terms of safety and health is important not only for legal or ethical reasons, but also for commercial reasons. On the other hand, every year, over 5500 people die in the EU from work accidents, and another 159000 people die as a result of occupational diseases [1]. EU companies lose about 143 million workdays each year due to workplace accidents. Estimates vary, but such accidents and illnesses are to cost the EU economy at least 490 billion Euros a year [2].

First, employers must promote a culture of health and safety to support employee participation. Workers, however, should not limit their cooperation only to passive participation and compliance with security rules. If workers wish to obtain the strongest protection for their health and safety, they should use all the modalities of participation in the workplace.

The main goal of this study is to analyze the safety culture in order to understand how theory and practice can be integrated to improve safety culture and related economic results. The research includes studies of the safety culture concept, factors that influence the

* Corresponding author: roland moraru@yahoo.com 
relationship between organizational culture and safety behavior and examine the differences in perception of safety culture in organizations. Globally, the results will generate relevant insight on how safety culture can be systematized theoretically and can provide a series of recommendations to guide the development of future interventions on safety culture.

We aim to answer some basic questions to deepen the theme: Is the work safety culture important? For whom could it be important? And how is it applicable? How does it work in organizations? What are the key parts of the equation and how can we apply them at best to continuously improve the working environment in a systematic and uniform way? Cumulating the responses to this question, we tried be able to setup a framework for indepth understanding of all the implications of OSH culture in practice.

\section{Literature review}

During the last 35 years, researchers demonstrated the increasing interest in the concept of safety culture due to its impact on safety results. Following several major disasters in the areas of nuclear, offshore drilling, and mining processes, safety culture was identified as a critical concept for organizations aimed at reducing on systematic bases the safety incidents in the workplace [3].

Researchers of safety culture in the workplace tend to use one of the existing two main approaches: interpretative or functionalist [4]. The interpretative vision considers culture as being an emergent property, which is a complex result generated by all employees, not just by top managers, and that culture cannot be "developed" fast, but it evolves through organizational learning in time [5].

Instead, the functionalist school sees culture as something that can be "manipulated" deliberately by management to support corporate interests and is largely generated by a top - down approach [6,7]. For example, a functionalist approach to culture should be reflected in comprehensive risk management processes, while an interpretative approach can focus on developing the shared vision and identity of the organization's members.

Safety culture subsumes and appeals to a number of different disciplines of study and therefore remains a fragmented and confusing concept, insofar as there is currently no universally accepted definition [8]. [9] describes the concept of safety culture as ambiguous, with definitions often unclear and inconsistently applied.

In terms of safety culture content, we retain an approach derived from organizational culture theorists, selected culture is described as having three distinct layers, namely, basic assumptions (core), shared values (middle); and artifacts (outer layer) [10,11]. Each layer differs in terms of external visibility and awareness of its members selected, in the outer layers being easier to identify and measure through specific research tools. Guldenmund suggests a causal link between layers, using the most common terms of safety culture, safety climate and safety behavior. This causal link considers the combination of safety perceptions of individuals (safety climate) a consequence of the underlying assumptions of the members of an organization (safety culture). Early empirical research on safety culture and climate focused on exploring their multi-dimensional nature $[12,13]$. In one of the earliest studies on safety climate, Zohar, in year 1980, proposed a model with eight factors, which was later tested and refined in a three-factor model [12].

Various meanings were attributed to the safety culture concept, generating a lot of definitions [14-16]. Nevertheless, most of them are broad and implicit [10]. We can state that there is no unanimously accepted definition. Previous studies have shown that management commitment to safety represents a determining factor of employees' attitudes/behaviors related to risk $[5,8]$. 


\section{Safety culture. What is it?}

The lack of clarity around the concept of safety culture renders developing and implementing a safety culture increasingly difficult, so many important scholars of the field focuses on the concept of "climate". Some definitions frequently cited in the literature are shown in Table 1.

Table 1. Highly cited definitions of "safety culture"

\begin{tabular}{||l|l|l||}
\hline $\begin{array}{l}\text { Crt. } \\
\text { No. }\end{array}$ & Reference & \multicolumn{1}{c||}{ Definition } \\
\hline 1. & Uttal (1983) & $\begin{array}{l}\text { "common values and beliefs which interacts with an organisation } \\
\text { structures and control systems to produce norms of behavior." }\end{array}$ \\
\hline 2. & $\begin{array}{l}\text { Cox \& Cox } \\
(1991)\end{array}$ & $\begin{array}{l}\text { "safety culture reflect the attitudes, beliefs, values that employees } \\
\text { share them in relation to safety ". }\end{array}$ \\
\hline 3. & IAEA (1991) & $\begin{array}{l}\text { "set of characteristics and attitudes of organizations and individuals } \\
\text { who set as a first-rate priority that the safety issues of nuclear plants } \\
\text { will receive the attention guaranteed by their importance" }\end{array}$ \\
\hline 4. & $\begin{array}{l}\text { Pidgeon } \\
(1991)\end{array}$ & $\begin{array}{l}\text { "set of beliefs, norms, attitudes, roles and social and technical } \\
\text { practices aimed at minimizing the exposure of employees, managers, } \\
\text { clients and members of the public to conditions considered } \\
\text { dangerous or harmful" }\end{array}$ \\
\hline 5. & Geller (1994) & $\begin{array}{l}\text { "in a total safety culture, everyone feels responsible for safety and } \\
\text { pursues it as an ongoing goal" }\end{array}$ \\
\hline 6. & $\begin{array}{l}\text { Reason } \\
(2000)\end{array}$ & $\begin{array}{l}\text { "an ideal safety culture is the engine that continues to propel the } \\
\text { system towards health and safety objective, regardless of personality } \\
\text { or leadership of current commercial concerns. " }\end{array}$ \\
\hline 7. & $\begin{array}{l}\text { Cooper } \\
(2000)\end{array}$ & $\begin{array}{l}\text { "that the observable effort degree by which all members of the } \\
\text { organization keeps the attention of and action by the continuous } \\
\text { improvement of safety". }\end{array}$ \\
\hline 8. & $\begin{array}{l}\text { Guldenmund } \\
(2000)\end{array}$ & $\begin{array}{l}\text { "aspects of organizational culture that will impact on attitudes and } \\
\text { behaviors related to increase/reduce the risk." }\end{array}$ \\
\hline 9. & Hale (2000) & $\begin{array}{l}\text { "common attitudes, beliefs and perceptions shared by natural groups, } \\
\text { defining norms and values that determine how they act and react to } \\
\text { risks and risk control systems" }\end{array}$ \\
\hline 10. & $\begin{array}{l}\text { Mohammed } \\
(2003)\end{array}$ & $\begin{array}{l}\text { "a sub-facet of organizational culture that affects the attitudes and } \\
\text { behavior of workers in relation to an organization's continuing safety } \\
\text { performance" }\end{array}$ \\
\hline \hline Anays
\end{tabular}

Analyzing the definitions listed in Table 1, it becomes clear that many scientists understand the safety culture that is intrinsically linked to organizational culture, and the definitions are therefore quasi - similar to the corresponding definitions of organizational culture $[10,15,17,18]$. Some definitions specific put emphasis on safety $[7,19]$ and others indicate daily effort required to maintain safety standards [14, 20].

\section{Safety culture and management of uncertainty. A model proposal for Romania}

Although the main role detained by organizational culture in directing an organization's success or failure, one can find no apparent consensus on describing the culture of any organization [10]. Moreover, unsolved discussion persists as to whether organizations have or are a culture [21]. Consequently, it is hardly surprising that no acknowledged model of the safety culture exists. Evolutionary multifaceted and change management models of safety culture are reflecting the individual and organizational change and maturity level in terms of safety management [3, 22-24]. This approach is less focused on culture content 
and on mapping safety culture results, but aims to describe how individuals and organizations go through stages of change in terms of their approach to safety and risk management.

Hudson [25] proposes a model describing a hierarchy of cultural refinement in terms of safety. As shown in Figure 1, Hudson suggests that high levels of information and trust are critical for organizations to reach a mature safety culture in which safety values are integrated in the organization's philosophy and business practices.

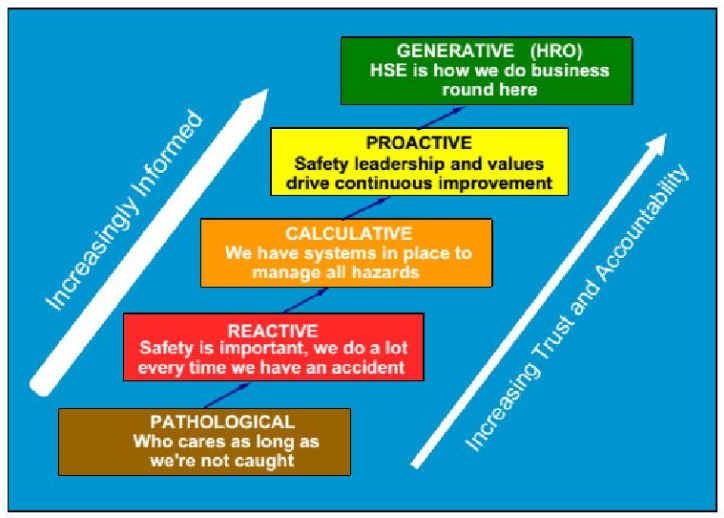

Fig. 1. Evolutionary safety culture maturity model [25]

The development was based on [26] typology on three levels of culture - pathological bureaucratic and generative - and [7], who proposed the extension, including two additional levels, reactive and proactive. Hudson also applied this model (renamed "the safety culture ladder", 2007) to the implementation of safety culture in a major multinational oil company. Known as the "Hearts and Minds" project, Hudson used the OSH culture scale as a tool for consultation to gain support from senior management in developing a culture of safety and to monitor progress over time.

In terms of individual behavior, [27] believes that individual safety performance should be composed of two components: safety compliance safety and safety participation. Safety compliance refers to people adhering to safety procedures and to conduct operations in a safe manner, while participation refers to helping co-workers, promotion of the safety at work, demonstrating initiative and submitting efforts to improve workplace safety [28, 29] Namely, safety compliance can be considered a core activity for the safety of an individual, while participation in involves a behavioral conduct that has no direct impact on the safety of an individual, but contribute to the development of an environment that supports longterm security ( Figure 2).

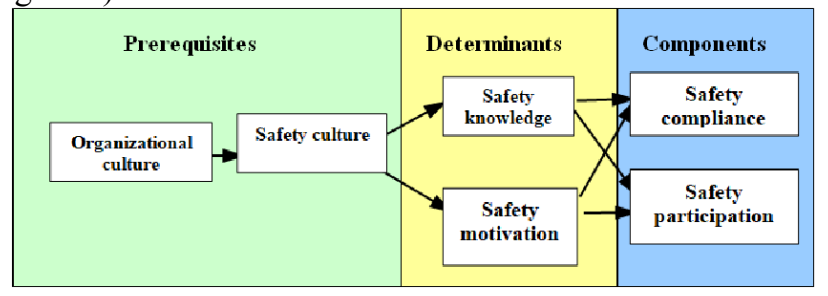

Fig. 2. Safety performance framework

From this point of view the discussion of safety culture appears in a new light. Culture from this perspective is considered more as a tool to provide enough coordination/integration of otherwise autonomous activities than as a general assurance of the core value of safety. This thinking can be sketched in a socio-technical safety culture 
model. Connecting safety management systems, organizational culture, and socio-technical systems design in the manner suggested in Figure 3, helps to surpass shortcomings of existing safety culture models in order to apply them in Romanian organizations.

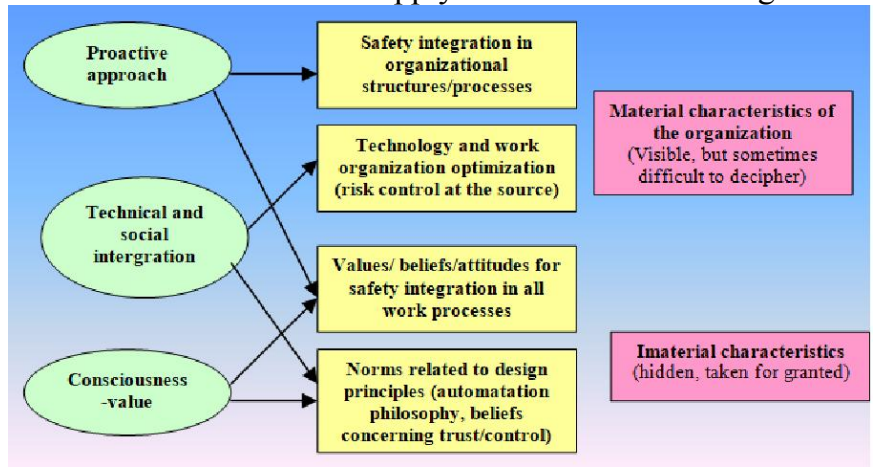

Fig. 3. Safety culture model from socio-technical perspective

In view of this simple model, we propose a series of indicators to measure safety culture of any organization, as follows:

\section{a. Proactive approach in promoting safety}

- Strategic and/or operational safety goals for all company departments;

- Resource planning for promotion of safety;

- Measuring negative and positive safety indicators;

- Institutionalized continuous improvement;

- Adapted change management for positive organizational change.

b. Socially and technically integrated system's design

- Task-adequate technical and organizational safety systems;

- Self-regulation in small control loops;

- Worker's individual motivation through orientation of working task;

- Safe technical systems.

\section{c. Actions with consciousness value}

- Individual/collective actions reflecting safety awareness;

- Reflection on the equilibrium between centralized and decentralized autonomy and control;

- Participative decision-making and change processes;

- Freedom in questioning attitudes regarding practices and/or guidelines.

On this basis, more detailed safety culture indicators can be derived, to develop a questionnaire to support safety management and safety culture audits in Romanian companies.

\section{Are behavior based safety and safety culture change divergent?}

Two distinct approaches to OHS management have generated a significant amount of debate or even controversy during the last 15 years. Behavior-based safety (BBS) is focused on the identification and modification of critical safety behaviors, emphasizing how such behaviors are connected to workplace injuries. The second approach emphasizes the basic importance of the safety culture and how it shapes/influences safety behaviors and the effectiveness of safety programs. 
BBS management is basically an extension of applied behavior analysis, seen as a continuous process. Culture change approaches come largely from management and organizational behavior theory. Table 2 gives a synthesis of main features of the two approaches.

Table 2. Synthesis of main features of BBS and safety culture change

\begin{tabular}{|l|l|l|}
\hline \multicolumn{1}{|c|}{ Feature } & \multicolumn{1}{|c|}{ BBS } & \multicolumn{1}{c|}{ Safety culture change } \\
\hline Origin & Psichology/behavior modification & Organizational behavior \\
\hline \multirow{4}{*}{ Key apects } & Bottom-up & Top-down \\
\cline { 2 - 3 } & Analytic & Intuitive \\
\cline { 2 - 3 } (typical) & Setting specific & Setting specific \\
\cline { 2 - 3 } & Continuous process & Self-sustained process \\
\hline \multirow{4}{*}{ Main strenghts } & Critical behaviors identification & Assess values, beliefs, assumptions \\
\cline { 2 - 3 } & Set performance goals & Plan alternative vision \\
\cline { 2 - 3 } & Observe behaviors & $\begin{array}{l}\text { Work to implement change } \\
\text { (leadership and workers) }\end{array}$ \\
\cline { 2 - 3 } & Feed-back/reinforcement & \\
\cline { 2 - 3 } & Specific technology & Emphasize organizational change \\
\cline { 2 - 3 } & Empirical/objective & Focus on basic causes \\
\cline { 2 - 3 } & Frontline workers focus & Participatory (often) \\
\cline { 2 - 3 } & Participatory (usual) & Comprehensive \\
\hline Main weaknesess & Victim blaming & Diffuse technology \\
\cline { 2 - 3 } & Minimizes environment & Subjective/intuitive \\
\cline { 2 - 3 } & Focus on immediate causes & Indirect \\
\hline
\end{tabular}

First of all, behavior change and culture change are intervention strategies aimed at improving safety performance. Workplace injury causation is frequently described as a sequence of stages. As highlighted in Figure 4, exposures, ( unsafe conditions and/or unsafe behaviors), represent the immediate causes of most workplace accidents.

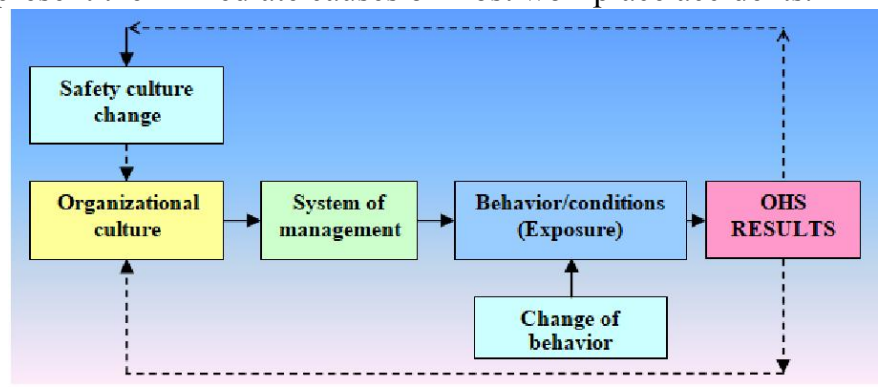

Fig. 4. Safety management. A sequential model

Despite that BBS and safety culture change may agree on the benefits of achieving a positive and participatory culture for safety, they obviously differ on how this target can be achieved. But they can be considered complementary to the extent that their respective strengths can be joined and their disadvantages minimized or eliminated.

It should be possible to highlight the culture change process in terms of stages that could be monitored and used to measure progress/impact. Figure 5 gives a map of these two tasks and emphasize this integration. Improving the organizational safety culture can be considered to be a significant outcome for both for BBS and for culture change approaches. The culture change process related to the integrative approach presented in Figure 5 is more comprehensive in problem identification, data-based, opened and participatory in implementation. The improvement process can originate both at the top or at the bottom of the organization, so it could represent a starting point for Romanian organizations. 


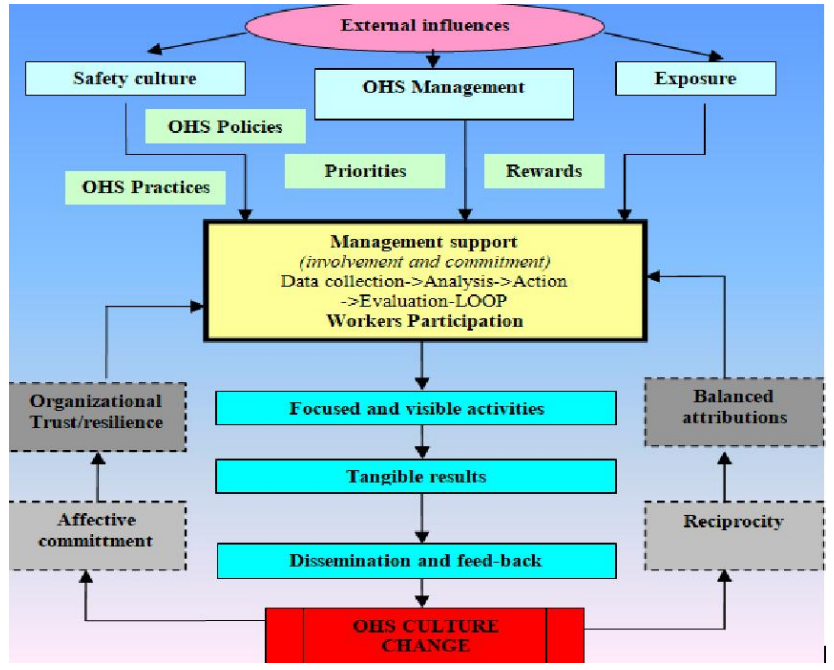

Fig. 5. Roadmap of the integrative approach to OHS safety management: a proposal for Romanian companies

\section{Conclusion}

Presently, there is large recognition in the literature that safety culture is a basic element in the organization's efforts to prevent occupational injuries and illnesses. The main aim of this paper is to submit to the Romanian specialists in health and safety at work the safety culture concept and to highlight a set of basic issues associated with it, hoping not only to reduce possible ambiguities but also to stimulate the development of safety culture and participatory and proactive occupational risk management in Romanian companies. From the perspective of industrial companies, questions may persist regarding the difference between operational elements of safety culture and their connection with the results at different levels in an organization.

Research efforts have remained, historically, focused on ambiguous debates regarding conceptual distinctions and size of influence factors rather than on the relevant industry results, such as building integrative multi-method useful to understand the depth of risk management directions and performance-based culture and to facilitate industry practices. However, the current need remains to integrate theory with practice, to highlight differences in level of organization, to map the relationship between safety culture and behavior-based safety, and translate relevant applied research in solutions for industrial organizations. By all means, to minimize injuries, save lives and target towards zero incidents, both researchers and practitioners must pay more attention to this vital topic of „safety culture". The efficiency of a safety management system depends on its capacity to encourage the participation of the workforce and thus decentralize decision-making. This, in turn, provides the flexibility in risk management.

\section{References}

1. EU-OSHA, Leadership and management skills on safety and health at work. A practical guide (in Romanian), ISBN 978-92-9191-633-7, DOI:10.2802/39306 (2012)

2. European Commission, Causes and circumstances of accidents at work in the EU, (2009)

3. L.I Cioca, R. Moraru, Psychosocial occupational risk management,,"Lucian Blaga" University Publishing House, Sibiu, 2010). 
4. S. Clarke, Personnel Review, 35 (4), 413-430 (2006)

5. S. J. Cox, A. J. T. Cheyne, Safety Science, 34, 111-129 (2000)

6. A. Hopkins, Making safety work. Australia: Allen and Unwin. (1995)

7. J. Reason, Western Journal of Medicine, 172 (6), 393-396. doi:10.1136/ewjm.172.6.393 (2000)

8. D. Zohar, Accident Analysis and Prevention, 42 (5), 1517-1522 (2010)

9. A. I. Glendon, Managing Safety Risks, in M. O'Driscoll, P. Taylor, \& T.Kalliath, (Eds.), Organisational Psychology in Australia and New Zealand (pp. 212-238). Australia: Oxford University Press (2003)

10. F.W. Guldenmund, Safety Science, 34, 215-257 (2000)

11. E. H. Schein, Organisational Culture and Leadership, 2nd Edition. Jossey-Bass: San Francisco (1992)

12. R. L. Brown, H. Holmes, Accident Analysis and Prevention, 18, 455-470 (1986)

13. L. Ivascu, B. Cirjaliu, A. Draghici, 3rd Global Conference on Business, Economics, Management and Tourism (BEMTUR) Italy, 39, pp. 674-678 (2015)

14. M. D. Cooper, Safety Science, 36, 111-136 (2000)

15. S. J. Cox, T.R. Cox, Work \& Stress, 5, 93-106 (1991)

16. N. F. Pidgeon, Journal of Cross-Cultural Psychology, 22, 129-140 (1991)

17. A. R. Hale, Culture's confusions (Editorial). Safety Science, 34, 1-14 (2000)

18. S. Mohamed, Journal of Construction Engineering and Management, 128 (5), 375-384 (2002)

19. International Atomic Energy Agency (IAEA). Safety Culture. Report 75-INSAG-4 International Nuclear Safety Advisory Group of the International Atomic Energy Authority, Vienna (1991)

20. E. S. Geller, J. R. Rodd, M. J .Kalsher, F. M. Streff, G. R. Lehman, Journal of Safety Research, 18, 1-17 (1987)

21. M. Cioca, L. I. Cioca, 3rd IEEE International Conference on Industrial Informatics, INDIN, 1560381, pp. 230-233 (2005)

22. R. Moraru, Current Trends and Future Developments in Occupational Health and Safety Risk Management, Risk Management for the Future - Theory and Cases, Dr Jan Emblemsvåg (Ed.), InTech, DOI: 10.5772/1809 (2012)

23. R.I. Moraru, G.B. Băbuț, L.I. Cioca, Proceedings of the 17th International Conference - The Knowledge-Based Organization: Management and Military Sciences, pp. 735-740, (2011)

24. R.I. Moraru, G.B. Băbuţ, L.I. Cioca, Proceedings of the 5th International Conference on Manufacturing Science and Educations - MSE 2011, Volume II, pp. 363-366, Sibiu, Romania (2011)

25. P. Hudson, Implementing a safety culture in a major multi-national. Safety Science, 25, 697722. (2007)

26. R. Westrum, ICAO Journal, 51 (8), 6-8 (1996)

27. A. Neal, M. A. Griffin, P. M. Hart, Safety Science, 34, 99-109 (2000)

28. D. Pasculescu, L. Pana, V. M. Pasculescu, F. Deliu, Mining of Mineral Deposits, 13, (2),1-16, (2019)

29. C. Dura, I. Drigă, C. Isac, Engineering and Management Journal, 16 (6), 1269-1274, (2017) 